\title{
National Institute for Health and Care Excellence clinical guidelines development principles and processes
}

\author{
Madalina Garbi
}

Department of Cardiology, Royal Papworth Hospital, Cambridge Biomedical Campus, Cambridge, UK

\section{Correspondence to} Dr Madalina Garbi, Department of Cardiology, Royal Papworth Hospital, Cambridge CB2 OAY, UK; madalina.garbi@nhs.net

Received 26 January 2021 Revised 9 February 2021 Accepted 10 February 2021 Published Online First 23 February 2021

\section{SLinked}

- http://dx.doi.org/10.1136/ heartjnl-2021-319176

Check for updates

(C) Author(s) (or their employer(s)) 2021. No commercial re-use. See rights and permissions. Published by BMJ.

To cite: Garbi M. Heart 2021:107:949-953.

\section{ABSTRACT}

Clinical guidelines are developed by professional societies and also, in England, by an independent non-departmental public body, the National Institute for Health and Care Excellence (NICE). Similarities and differences between these guidelines should be viewed in the context of different objectives, responsibilities and roles of guideline developers. This review describes the NICE clinical guidelines development principles and processes with the aim to provide the reader an informed perspective on the recommendations made. NICE clinical guidelines are developed by an appointed independent advisory committee comprising healthcare professionals as well as lay members, supported by a professional team comprising project managers, information specialists, systematic reviewers and health economists. Furthermore, registered stakeholders comprising organisations that have an interest in the guideline topic, or represent people whose practice or care may be directly affected by the guideline, are consulted on the draft scope and draft guidelines. NICE selects a limited number of high impact questions to be answered by the review of evidence, rather than cover a certain topic exhaustively as the clinical guidelines developed by professional societies may do. NICE clinical guidelines recommendations reflect both the clinical effectiveness and the cost-effectiveness of interventions.

\section{INTRODUCTION}

Clinical guidelines developed by professional societies aim to be comprehensive and extensive accounts of state-of-the-art clinical practice within the scope of the respective professional society, based on evidence as well as on expert opinion. ${ }^{12}$ The authors are nominated individuals, selected for their expertise. The professional societies developing the guidelines can be national societies, addressing healthcare in a particular field within common national borders, for example the American College of Cardiology and the American Heart Association. They can also be multinational societies, addressing healthcare in a particular field across several countries, for example the European Society of Cardiology and the European Association for Cardio-Thoracic Surgery.

In the development of clinical guidelines, professional societies are not concerned with availability of resources or cost and they are not directly responsible for guidelines implementation. The implementation of those guidelines varies with the healthcare system, the health insurance system and socioeconomic constraints affecting a particular nation or a certain individual. It also varies with availability of services, expertise and technological resources. Cost-effectiveness is addressed by the Appropriate Use Criteria (AUC). AUC were first defined in the American healthcare system ${ }^{3}$ to address the overuse and underuse of healthcare resources. The American College of Cardiology established an AUC Taskforce ${ }^{4}$ for the development of AUC, for example, in the field of heart valve disease. The European Society of Cardiology and the European Association of Cardiovascular Imaging have also recognised the need to define AUC, to facilitate the best use of healthcare resources across Europe..$^{56}$ AUC refer to a limited number of carefully chosen high impact clinical scenarios and do not exhaustively cover the scope of clinical practice in a particular field.

In England, clinical guidelines are developed by the National Institute for Health and Care Excellence (NICE), an independent, non-departmental public body. As part of a wider remit covering the fields of healthcare, social care and public health, NICE is responsible for providing evidence-based clinical guidelines to help health professionals deliver the best possible care in the publicly funded National Health Service (NHS). The NICE clinical guidelines take into consideration individual needs as well as the needs of the overall population, aiming to achieve the most benefit for the greatest number of people, with fair distribution of available resources, based on consistent decision-making across different clinical topics. The role of NICE is to improve outcomes for people using the NHS and other public health and social care services. The NHS has a defined budget and appropriate use of resources is important. NICE methods therefore aim to focus resources on interventions that have been proven to be effective and cost-effective.

With their unique, highly valued and highly respected nature, the NICE clinical guidelines cover attributes of both AUC and clinical guidelines developed by professional societies. They should be analysed and appraised in the light of their specific purpose, and of the NICE principles (see https:// www.nice.org.uk/about/who-we-are/our-principles\#the-principles-that-guide-nices-work) they follow and promote (box 1), not by comparison with other clinical guidelines and clinical recommendations documents.

\section{NICE CLINICAL GUIDELINES DEVELOPMENT PROCESS}

The NICE clinical guidelines topics are selected in collaboration with NHS England, the Department 
Box 1 The NICE principles

\section{Principles of guidelines development}

- Topics reflect national health priorities.

- The development process is described in a regularly updated manual.

- The recommendations are developed by an independent advisory committee.

- Involves patients, advocates, healthcare professionals, commissioners, providers and the public.

- Offers stakeholders the opportunity to influence recommendations (consultation).

Principles underpinning recommendations

- Relevant, reliable and robust evidence.

- Cost-effectiveness and population benefit.

- Specific recommendations for subgroups with specific effectiveness and cost-effectiveness.

- Research recommendations for evidence gaps and uncertainties.

Principles underpinning the guidelines aims

- Support innovation.

- Reduce health inequalities.

Principles of guidelines implementation and update

- Publish, disseminate and provide support for implementation.

- Update recommendations in line with new evidence.

NICE, National Institute for Health and Care Excellence.

of Health and Social Care, and Public Health England to reflect national health priorities. The selection process takes into consideration the prevalence of a certain condition or disease, predicted change in prevalence, impact on health and wellbeing, robustness of existent evidence, variation in the provision of care and the potential to reduce health inequalities.

The NICE clinical guidelines development process is described in a regularly updated manual, ${ }^{7}$ ensuring decision-making transparency and accountability.

\section{Guidelines committees}

The guideline recommendations are developed by an appointed independent advisory committee comprising healthcare professionals as well as lay members. A committee chair with expertise and skills in chairing groups, but without expertise in the topic of the guidelines, is appointed to facilitate balanced participation of committee members in discussions. A topic adviser with specialist knowledge and expertise in the topic can be appointed to work closely with the NICE guidelines development team on the development of the scope, on the evidence reviews and health economic reviews, and on the writing and editing of guideline documents. The topic adviser is also a member of the guidelines committee. All members of the guidelines committee have to declare potential conflicts of interest before their appointment and when changes occur; this includes direct and indirect, financial and non-financial conflicts of interest. Conflicts of interest may prevent appointment of an individual as guidelines committee member or restrict participation to the development of certain recommendations. For example, research interest and publications regarding the subject of a particular recommendation qualify as a direct non-financial conflict of interest because the individual may gain professional benefit as a consequence
Table 1 NICE guidelines registered stakeholders

\begin{tabular}{|c|c|}
\hline \multicolumn{2}{|l|}{ Stakeholder category } \\
\hline $\begin{array}{l}\text { National organisations for people using } \\
\text { services, carers and the public }\end{array}$ & $\begin{array}{l}\text { National patient, user or carer groups. } \\
\text { National charities. }\end{array}$ \\
\hline $\begin{array}{l}\text { National organisations representing } \\
\text { practitioners }\end{array}$ & $\begin{array}{l}\text { Royal colleges. } \\
\text { Medical associations. } \\
\text { Professional associations. }\end{array}$ \\
\hline $\begin{array}{l}\text { Public sector providers and } \\
\text { commissioners }\end{array}$ & $\begin{array}{l}\text { NHS trusts. } \\
\text { Clinical commissioning groups. } \\
\text { GP practices. } \\
\text { Local authorities. }\end{array}$ \\
\hline \multicolumn{2}{|l|}{ Local Healthwatch organisations } \\
\hline $\begin{array}{l}\text { Organisations that fund or carry out } \\
\text { research }\end{array}$ & $\begin{array}{l}\text { Funding councils. } \\
\text { Universities based within the UK. } \\
\text { International organisations that fund } \\
\text { or carry out research within the UK or } \\
\text { on UK populations. }\end{array}$ \\
\hline $\begin{array}{l}\text { Private, not-for-profit, voluntary } \\
\text { providers of care or services }\end{array}$ & $\begin{array}{l}\text { Private providers. } \\
\text { Not-for-profit providers. } \\
\text { The voluntary sector. } \\
\text { Providers of care. } \\
\text { Other independent providers. }\end{array}$ \\
\hline $\begin{array}{l}\text { Manufacturers and commercial } \\
\text { industries }\end{array}$ & $\begin{array}{l}\text { Companies that manufacture } \\
\text { medicines, devices, equipment or } \\
\text { adaptations. } \\
\text { Commercial industries relevant to } \\
\text { public health. }\end{array}$ \\
\hline $\begin{array}{l}\text { Government departments and national } \\
\text { statutory agencies }\end{array}$ & $\begin{array}{l}\text { Department of Health and Social Care } \\
\text { Public Health England. }\end{array}$ \\
\hline $\begin{array}{l}\text { Overseas agencies with a remit covering } \\
\text { the UK }\end{array}$ & $>$ WHO. \\
\hline
\end{tabular}

of the recommendation, increasing or maintaining their professional reputation.

The guidelines committee is supported by a professional team comprising project managers, information specialists, systematic reviewers and health economists. Support is also provided at different stages of the development process by the NICE editorial team, media relations team, resource impact assessment team, adoption and impact team, public involvement programme and publishing team.

\section{Stakeholders}

NICE involves healthcare professionals, providers and commissioners of healthcare, patients, advocates and the public in clinical guidelines development (table 1). To be involved, organisations that have an interest in the guideline topic, or represent people whose practice or care may be directly affected by the guideline, register with NICE as registered stakeholders. Registered stakeholders are offered the opportunity to comment on the draft scope and draft guidelines through consultation and they support implementation of the guidelines once published. NICE formally responds to comments from registered stakeholders and publishes the responses on the NICE website.

\section{Guidelines scope}

The NICE clinical guidelines development process begins with the development of the scope, to set out the population, settings and issues that will and will not be covered and to create a framework. The scope includes a brief description of the guideline topic and context, explaining why the guidelines are needed and what value they might add. Based on identified key issues, 
the scope selects, defines and lists a limited number of questions to be answered by the review of the evidence. In this, regard, the NICE clinical guidelines resemble AUC, which also select a limited number of high impact questions to answer, rather than covering the topic exhaustively as the clinical guidelines developed by professional societies may do. The questions are finalised following consultation on the draft scope with registered stakeholders.

\section{Clinical and health economic evidence}

The NICE clinical guidelines recommendations are based on relevant, reliable and robust evidence identified using systematic, transparent and reproducible literature searches aiming to minimise the effect of publication bias and database bias on the result of the review. The literature search protocols are developed by the information specialist and they are part of the review protocol signed off by the guidelines committee. The selection of sources and the review strategy depends on the requirements of the review question. The search terms used comprise a combination of subject headings and free-text terms. Limits and filters are used to obtain studies relevant to the review question. The search may be limited to a particular study design; for example, only randomised control trials may be accepted when the clinical effectiveness of two interventions is compared. Searches are repeated before completing the guidelines development process, to update the evidence with potentially new publications. The search strategy is quality-assured by a second information specialist to ensure consistently high standard for identifying evidence. Details of the search are published on the NICE website with the guidelines draft and with the final guidelines, for transparency and future reference.

The quality of the evidence is assessed for potential bias through internationally accepted methods of critical appraisal of study design, methods and certainty of findings. Analysis and presentation of results depend on the type of study. For studies assessing the effectiveness of an intervention, a meta-analysis may be performed and the results may be presented as a pooled estimate; if meta-analysis is not appropriate, forest plots can be used to show effect estimates and confidence intervals for each study and to provide a graphical representation. For studies assessing the accuracy of diagnostic tests, if meta-analysis is not appropriate, the results that are important for the review question may be presented in a narrative summary, summarised in tables or presented as receiver operating characteristic (ROC) curves. For studies of prognosis or clinical prediction models, the quality of the evidence is presented in a narrative summary and the results may be presented as tables. For studies of qualitative data, thematic analysis of the evidence tables is performed and second-level themes are derived.

The certainty or confidence in the review findings is assessed using the GRADE and GRADE-CERQual approach, evaluating certain features of the evidence found for each critical and important outcome or theme. The GRADE approach is used to assess the certainty of evidence for intervention studies, evaluating study limitations (risk of bias), inconsistency, indirectness, imprecision and other considerations, for example publication bias or study sponsorship (table 2). The GRADE-CERQual approach is used to assess the confidence of evidence for qualitative studies, evaluating methodological limitations, relevance, coherence and adequacy of data (table 3 ). The certainty or confidence of the evidence is classified as high, moderate, low or very low, and in the context of NICE guidelines it impacts on the recommendation made, as described in table 4. Standardised
Table 2 GRADE-assessed features of the evidence for intervention studies

\begin{tabular}{ll}
\hline Features assessed & \\
\hline $\begin{array}{l}\text { Study limitations (risk } \\
\text { of bias) }\end{array}$ & Internal validity of the evidence. \\
\hline Inconsistency & $\begin{array}{l}\text { Treatment effect estimates heterogeneity/variability } \\
\text { across studies. }\end{array}$ \\
\hline Indirectness & $\begin{array}{l}\text { Population, intervention, intervention comparator and } \\
\text { outcome of interest differences across studies. }\end{array}$ \\
\hline Imprecision & $\begin{array}{l}\text { Degree of support of a particular decision provided by the } \\
\text { effect estimate confidence. }\end{array}$ \\
\hline Other considerations & $\begin{array}{l}\text { Publication bias and the degree of selective publication } \\
\text { of studies. }\end{array}$ \\
\hline
\end{tabular}

statements are used to describe the strength of the evidence, for example 'no evidence', 'weak/moderate/strong evidence' and 'inconsistent evidence'.

A review of the economic evidence is carried out in parallel with the review of clinical evidence. In case of high degree of uncertainty in the economic evidence review and of high resource implications of an intervention, health economic modelling can be performed. Additional information may be required to inform health economic modelling. For example, the long-term impact of side effects of an intervention is important for health economic modelling and this information may not be provided by short-term or intermediate-term clinical trials.

A cost-effectiveness analysis measures a single overall health outcome, for example 'a life year saved', 'a death averted' or 'a patient-year free of symptoms', and assesses the cost per unit of outcome based on relevant prices. The main type of costeffectiveness analysis performed by NICE is cost-utility analysis. Cost-utility analysis evaluates the quality of life and length of life gained as a result of an intervention. The health effect is expressed as QALYs (quality-adjusted life years), an outcome measure obtained by adjusting the length of life gained as a result of an intervention to reflect the quality of life, by weighting each estimated year gained with a quality of life score. Consequently, 1 QALY equals 1 year of life in perfect health. The QALY is an outcome measure comparable between different populations and disease areas. To ensure equity, a QALY is deemed to be of equal value for NICE economic evaluations regardless of sociodemographic characteristics, age or level of health of individuals, without equity weighting.

NICE cost-effectiveness analysis takes into consideration cumulative costs and health effects over the timeline of the analysis (usually the projected lifetime of the target patient group), adjusting their value according to the time when they occur. Immediate costs as well as immediate health benefits of an intervention have a higher value than costs and health benefits occurring at a later date, reflecting the preference of individuals for immediate benefits and later costs. The present value of costs and benefits is calculated using an economic method known as

Table 3 GRADE-CERQual-assessed features of the evidence for qualitative studies

\begin{tabular}{ll}
\hline Features assessed & \\
\hline $\begin{array}{l}\text { Methodological limitations } \\
\text { Relevance }\end{array}$ & Internal validity of the evidence. \\
Coherence & Similarities and differences within the evidence. \\
Adequacy of data & Richness and quantity of the evidence. \\
\hline
\end{tabular}


Table 4 Impact of evidence certainty or confidence on the NICE guidelines recommendations

\begin{tabular}{|c|c|}
\hline $\begin{array}{l}\text { Evidence } \\
\text { certainty/ } \\
\text { confidence }\end{array}$ & Impact on NICE guidelines recommendation \\
\hline High & Further research is very unlikely to change the recommendation. \\
\hline Moderate & $\begin{array}{l}\text { Further research is likely to have important impact on confidence } \\
\text { and may change the strength of the recommendation. }\end{array}$ \\
\hline Low & $\begin{array}{l}\text { Further research is likely to have important impact on confidence } \\
\text { and is likely to change the recommendation. }\end{array}$ \\
\hline Very low & Further research will probably change the recommendation. \\
\hline
\end{tabular}

'discounting', using a certain annual discounting rate, usually $3.5 \%$ and usually the same annual rate for costs and health benefits. An intervention that accumulates health benefits over a long time might still not be cost-effective if there is a high upfront cost.

Sometimes identifying the most cost-effective intervention is straightforward because the least costly intervention in terms of NHS resource use is also the most effective at increasing QALYs. However, if the most effective intervention is more costly, then the ICER (incremental cost-effectiveness ratio) should be considered. Although there is no NICE ICER threshold excluding the recommendation of interventions, recommendations should increase effectiveness at an acceptable level of increased cost. Cost-effective interventions have ICER $<£ 20000$ per QALY gained. An ICER $>£ 20000$ but $<£ 30000$ may be acceptable, for example in the case of an innovative intervention that adds significant distinct benefits not captured by the cost analysis. NICE supports innovation; however, the additional cost of an innovative intervention diverts resources from established costeffective interventions and may not demonstrate the expected effectiveness. To mitigate this risk, NICE may recommend the use of an innovative intervention in the context of a managed access agreement that makes the intervention available at a discounted price for a limited time interval, pending the development of UK NHS effectiveness evidence. An ICER $>£ 30000$ per QALY gained would only be acceptable if deemed to represent an effective use of NHS resources because of certain strong evidence of particularly high effectiveness in the long term.

\section{Guidelines committee discussions and recommendations}

The NICE clinical guidelines include summaries of the clinical and health economic evidence underpinning recommendations and an account of the guidelines committee discussions of the evidence and of other factors taken into consideration, for example patient concerns, acceptability of interventions, availability of services and expertise.

The NICE clinical guidelines use the wording of recommendations to reflect the strength of the evidence; 'offer' is used to recommend an intervention with strong evidence of benefit and 'consider' is used to recommend an intervention with less certain benefit evidence. Research recommendations can be made to address evidence gaps and uncertainties.

NICE guidelines aim to reduce health inequalities, supporting strategies that improve the health of the population as a whole. To achieve this aim, NICE uses the process of equality impact assessment to identify subgroups with a health status disadvantage, geographical difficulties in access to health services and health inequalities arising from socioeconomic factors and behaviours. NICE principles allow for specific recommendations to be made for subgroups, considering the effectiveness and cost-effectiveness of an intervention specific to that subgroup. Recommendations for subgroups may therefore differ from those for the rest of the population.

The NICE clinical guidelines do not only address physicians and other healthcare professionals involved in the diagnosis and management of a certain condition; they also address patients, their families and carers, and organisations representing their interests. This explains the writing style of the guidelines, using clear, precise, concise and consistent wording and expressing concepts in a standard way without jargon. The language is person-centred, respectful, empathetic and inclusive.

\section{Draft guidelines consultation}

Registered stakeholders are offered the opportunity to influence the final recommendations through consultation, as part of the quality-assurance and peer-review processes. NICE encourages interaction with the stakeholders and may post questions for the stakeholders with the draft guidelines, seeking their views on potential equality impact, on potential substantial increase in costs, their justification for increase in cost and matters related to guidelines implementation. Stakeholders' comments are expected to be constructive, reasoned arguments aiming to improve the guidelines draft. NICE encourages stakeholders that share similar views on the guidelines to work together to produce a joint, consensus response, to be submitted by one stakeholder; all other stakeholders participating in the consensus should state their endorsement in their response to the consultation. For example, a consensus response of relevant British national societies could be submitted by the British Cardiovascular Society and endorsed by the other national societies in their response. NICE is a national public body striving for excellence within the constraints of public funding of standardised equitable healthcare that is free for all; thus, national consensus with the relevant professional societies for the topic of the guidelines is highly desirable.

\section{NICE GUIDELINES PUBLICATION AND IMPLEMENTATION}

Two weeks before publication, stakeholders who have commented on the draft guidelines are sent the final guidelines, the evidence reviews and a copy of the responses to the consultation; this allows stakeholders to highlight errors and prepare for publication and implementation, rather than make further comments. At the time of guidelines publication, evidence reviews, methods, NICE Pathway, key messages for the public and most support tools are also published on the NICE website. The NICE media relations team raises awareness of the guidelines by notifying stakeholders, publicising the guidelines through newsletters and alerts, issuing a press release or briefing, and using social media channels.

NICE supports clinical guidelines implementation by providing a visual summary or quick guide and a baseline assessment tool that organisations can use to identify whether they are in line with the recommendations and to plan and record activity accordingly. Other guidelines implementation resources and patient decision aids may be produced by NICE or may be produced by other organisations and endorsed by NICE.

\section{NICE CLINICAL GUIDELINES UPDATES}

Following their initial publication, the NICE clinical guidelines are updated in line with new evidence. NICE performs a comprehensive and extensive standard check of published guidelines every 5 years; however, it reacts to events at any time after initial 
publication. To identify events, NICE establishes surveillance of new relevant evidence, of new relevant interventions, of new related NICE guidance and of changes in context, for example changes in policy, infrastructure, legislation or costs. NICE maintains an event tracker, for example, of relevant ongoing studies. Recommendations update may be made for instance in case of publication of new evidence or of a safety update from the Medicines and Healthcare products Regulatory Agency.

\section{CONCLUSION}

Taking into consideration individual needs as well as the needs of the overall population, the NICE clinical guidelines recommendations reflect both the clinical effectiveness and the costeffectiveness of interventions. To finalise the recommendations, NICE encourages interaction with the registered stakeholders and national consensus with the relevant professional societies.

\section{Twitter Madalina Garbi @MadalinaGarbi}

Contributors MG is the sole author of this review.

Funding The authors have not declared a specific grant for this research from any funding agency in the public, commercial or not-for-profit sectors.

Disclaimer The views expressed in this publication are those of the author and not necessarily those of NICE.

Competing interests MG is the NICE topic advisor on heart valve disease.
Patient and public involvement Patients and/or the public were not involved in the design, or conduct, or reporting, or dissemination plans of this research.

Patient consent for publication Not required.

Provenance and peer review Commissioned; externally peer reviewed.

ORCID iD

Madalina Garbi http://orcid.org/0000-0001-9520-8186

\section{REFERENCES}

1 American College of Cardiology Foundation and American Heart Association, Inc Methodology manual and policies, from the ACCF/AHA Task force on practice guidelines, 2010.

2 European Society of Cardiology. Governing policies and procedures for the writing of ESC clinical practice guidelines, 2017.

3 Fitch K, Bernstein SJ, Aguilar MD, et al. The RAND/UCLA Appropriateness Method User's Manual. Prepared for Directorate General XII, European Commission. Santa Monica, CA: RAND, 2001

4 Hendel RC, Lindsay BD, Allen JM, et al. ACC appropriate use criteria methodology: 2018 update: a report of the American College of Cardiology Appropriate Use Criteria Task Force. J Am Coll Cardiol 2018;71:935-48.

5 Garbi M, Habib G, Plein S, et al. Appropriateness criteria for cardiovascular imaging use in clinical practice: a position statement of the ESC/EACVI Taskforce. Eur Heart J Cardiovasc Imaging 2014;15:477-82.

6 Delgado V, Cardim N, Cosyns B, et al. Criteria for recommendation, expert consensus, and appropriateness criteria papers: update from the European association of cardiovascular imaging scientific documents Committee. Eur Heart J Cardiovasc Imaging 2018;19:835-7.

7 National Institute for Health and Care Excellence. Developing NICE guidelines: the manual. London: National Institute for Health and Care Excellence, 2014. https://www. nice.org.uk/process/pmg20/chapter/introduction-and-overviewoping 